\title{
RELAÇÃO DA QUALIDADE DO SONO E DESEMPENHO ACADÊMICO DE JOVENS UNIVERSITÁRIOS
}

\section{RELACIÓN DE CALIDAD DEL SUEÑO Y DESEMPEÑO ACADÉMICO DE LOS JÓVENES UNIVERSITARIOS}

\section{RELATIONSHIP BETWEN SLEEP QUALITY AND ACADEMIC PERFORMANCE OF COLLEGE STUDENTS}

\begin{abstract}
Jamilly Henrique Costa da Silva ${ }^{1}$; Jadna Emille da Silva Arruda²; Natália de Castro e Silva Martins ${ }^{3}$; Luciana Moraes Studart Pereira ${ }^{4}$
\end{abstract}

DOI: $\underline{\text { https://doi.org/10.31692/978-65-991061-9-4.75-80 }}$

\section{INTRODUÇÃO}

O estado fisiológico denominado sono é responsável pela restauração do organismo humano necessária à sobrevivência. Alterações no seu padrão podem acarretar sequelas na habilidade de adaptação, humor, comportamento, função psicológica e desempenho das atividades diurnas (SANTOS, 2013). Dentre outros acontecimentos fisiológicos, durante o período do sono, o organismo produz proteínas para fortalecer e aumentar redes neuronais ativas necessárias à consolidação da memória e aprendizado, favorecendo a liberação de hormônios que promovem bem-estar (VALLE et al., 2009).

A privação do sono pode acarretar consequências importantes para a saúde e estabelece relação com o aumento de fadiga, sonolência diurna, alteração do humor, memória e atenção (ABS, 2018). Noites de sono não recuperadas apresentam associação também com lentificação no raciocínio matemático, diminuição da concentração e pensamento, comprometimento e transtornos cognitivos, dificuldades nos relacionamentos familiares, restrição da participação em atividades sociais e sinais de irritabilidade, ou até mesmo euforia à estímulos considerados neutros (VALLE, 2011).

Diante disso, o interesse em relação ao padrão de sono de estudantes universitários tem aumentado, pois a privação do sono e os distúrbios do sono são queixas comuns neste período (BARDINI, 2017). Por isso, se faz cada vez mais necessária a análise da qualidade de sono dessa faixa etária, uma vez que acadêmicos estão sujeitos à alterações do seu padrão de sono, em razão das exigências sociais da idade, hábitos noturnos e a necessidade de manter a vigília

\footnotetext{
${ }^{1}$ Graduanda em Fonoaudiologia pela Universidade de Pernambuco, jamillycostafono@ hotmail.com

${ }^{2}$ Graduanda em Fonoaudilogia pela Universidade de Pernambuco, jadnaemylle@ hotmail.com

${ }^{3}$ Fonoaudióloga Graduanda pela Universidade Federal de Pernambuco, natcsmartins@ hotmail.com

${ }_{4}$ Docente do Curso de Fonoaudiologia da Universidade Federal de Pernambuco, luciana.studart@uol.com.br
} 
durante o dia, e, no caso dos universitários, das modificações que o ingresso no curso de graduação confere ao seu estilo de vida (ALMEIDA, 2011). Adolescentes e universitários que não possuem boa qualidade de sono estão propensos a desencadearem déficits na aprendizagem, comprometimento na capacidade de resolução de problemas, distúrbios de saúde física e mental, alterações nos desempenhos das funções cognitivas e psicossociais (VASCONCELOS et al, 2013).

Ante o exposto, o objetivo desta investigação é relacionar a qualidade do sono de jovens universitários aos seus respectivos desempenhos acadêmicos. Acredita-se que conhecer o panorama da qualidade do sono de adolescentes e jovens universitários, e a relação com o desempenho escolar poderá contribuir de maneira contundente para os estudos da saúde do sono, bem como para o direcionamento de medidas preventivas aos distúrbios do sono em adolescentes e universitários.

\section{FUNDAMENTAÇÃO TEÓRICA}

O sono é definido como um processo neuroquímico que envolve centros cerebrais específicos para promover o adormecer e o acordar. É uma função biológica de extrema importância para o funcionamento normal do sistema nervoso (MAGALHÃES et al., 2007).

Os seres humanos são orientados por ciclos diários com distinção entre o dia e a noite e apresentam preferências, geneticamente determinadas, no que diz respeito aos horários de dormir e acordar. Pessoas consideradas matutinas preferem dormir cedo e acordam cedo, já as vespertinas têm preferência por dormir mais tarde e de despertar mais tarde e as intermediárias ocupam uma posição mediana. Assim como a preferência individual de horários para acordar e adormecer, existem variações particulares com relação à facilidade de execução das funções cognitivas, que também variam com o cronotipo de cada indivíduo.

Essas preferências podem estar associadas ao funcionamento individual do organismo ou a questões relacionadas à rotina e comportamento de cada indivíduo. (FINIMUNDI, 2012). Por exemplo, o período da juventude é marcado por um distúrbio fisiológico denominado atraso de fase, que caracteriza-se, além da necessidade de maior número de horas, pela preferência em ir dormir mais tarde e acordar também mais tarde. Jovens apresentam maior propensão em manter hábitos inadequados, com rotinas noturnas, sedentarismo, uso excessivo de dispositivos eletrônicos, estimulantes de vigília, entre outros fatores, que podem colaborar para que eles deitem mais tarde e durmam menos e fiquem mais sonolentos durante o dia (BARDINI, 2017). Diante de tais preferências, pode acontecer a privação do sono que acarreta consequências importantes para a saúde e estabelece relação com fadiga, sonolência diurna, alteração do 
humor, memória e atenção (ABS, 2018).

Dessa forma, a qualidade do sono pode ser prejudicada de forma transitória ou crônica. Em casos em que a irregularidade do sono se torne duradoura, investigações de distúrbios do sono, como por exemplo, a insônia e apneia do sono, fazem-se necessárias (VALLE, 2009). Além disso, a irregularidade no padrão de sono de adolescentes e universitários pode repercutir negativamente na saúde desses jovens e trazer transtornos para o desempenho acadêmico (SCHNEIDER et al, 2010).

Sabe-se que a juventude é um período de desenvolvimento muito importante para a determinação da carreira acadêmica e profissional dos indivíduos, além da expectativa existente de garantir uma boa qualidade de vida no futuro (STEA, 2014). Para que problemas relacionados à saúde e desempenho acadêmico de jovens universitários sejam minimizados, é de extrema importância que as funções executivas estejam funcionando corretamente. Diante disso, se faz alarmante a necessidade de fatores que contribuam para que esses resultados almejados como a boa qualidade de sono (OWENS, 2014).

\section{METODOLOGIA}

\section{Tipo de estudo}

Tratou-se de um estudo analítico, observacional e de corte transversal.

\section{População do Estudo}

A amostra foi composta por conveniência. Participaram do estudo 150 indivíduos jovens, de ambos os sexos, de cursos da área da saúde de uma universidade pública, com idade média de 22,83, desvio padrão de 3,77 anos e mediana igual a 22,00 anos.

\section{Coleta dos dados}

Os indivíduos foram convidados a participar da pesquisa, e, em seguida, houve a explicação sobre o conteúdo e os objetivos do trabalho e proposta a assinatura do Termo de Consentimento Livre e Esclarecido. Primeiramente, os participantes responderam ao instrumento de coleta contendo informações sobre dados pessoais, informações acadêmicas, hábitos de vida e saúde. Na sequência, preencheram questionário de Pittsburgh, que avalia a qualidade do sono em boa, ruim ou com presença de distúrbio do sono (BUYSSE, et.al, 1989).

\section{RESULTADOS E DISCUSSÕES}

Dos resultados relativos à relação entre a qualidade do sono e o desempenho acadêmico 
da população estudada, pode-se verificar na Tabela 1 que a qualidade do sono mostrou associação significativa com as variáveis "cansaço durante as aulas" e "cochilos durante as aulas" e para as referidas variáveis se destacam as maiores diferenças percentuais. $\mathrm{Na}$ primeira variável citada o maior percentual dos que responderam "às vezes" foi mais elevado entre os que tinham boa qualidade do sono e menos elevado entre os que tinham distúrbio do sono $(60,0 \%$ x 21,9\%), enquanto que o percentual na categoria "muitas vezes / sempre" foi mais elevado nos que tinham o citado distúrbio $(78,1 \%$ x 58,3\%); na variável cochilos durante as aulas o percentual dos que responderam "nunca / raramente", foi mais elevado entre os que tinham qualidade de sono boa quando comparados aos com distúrbio do sono (73,3\% x 25,0\%). Já o percentual que responderam "muitas vezes / sempre" foi mais elevado entre os que tinham distúrbio $(37,5 \%)$ e foi nulo entre os que tinham boa qualidade do sono.

Tabela 1 - Avaliação da qualidade do sono, segundo o resultado do desempenho acadêmico

\begin{tabular}{|c|c|c|c|c|c|c|c|}
\hline \multirow{3}{*}{ Variável } & \multicolumn{6}{|c|}{ Qualidade do sono } & \multirow{3}{*}{ Valor $\mathbf{p}$} \\
\hline & \multicolumn{2}{|c|}{ Boa } & \multicolumn{2}{|c|}{ Ruim } & \multicolumn{2}{|c|}{ Distúrbio } & \\
\hline & n & $\%$ & $\mathbf{n}$ & $\%$ & $\mathbf{n}$ & $\%$ & \\
\hline Desempenho acadêmico & & & & & & & $\mathrm{p}^{(1)}=0,926$ \\
\hline Péssimo / Ruim & - & - & 2 & 1,9 & - & - & \\
\hline Razoável & 4 & 26,7 & 26 & 25,2 & 10 & 31,3 & \\
\hline Bom / Ótimo & 11 & 73,3 & 75 & 72,8 & 22 & 68,8 & \\
\hline Tem reprovação & & & & & & & $\mathrm{p}^{(2)}=0,474$ \\
\hline Sim & 5 & 33,3 & 33 & 32,0 & 14 & 43,8 & \\
\hline Não & 10 & 66,7 & 70 & 68,0 & 18 & 56,2 & \\
\hline Realização de avaliação final & & & & & & & $\mathrm{p}^{(2)}=0,104$ \\
\hline $\operatorname{Sim}$ & 13 & 86,7 & 80 & 77,7 & 30 & 93,7 & \\
\hline Não & 2 & 13,3 & 23 & 22,3 & 2 & 6,3 & \\
\hline Faltas frequentes & & & & & & & $\mathrm{p}^{(2)}=0,423$ \\
\hline $\operatorname{Sim}$ & 1 & 6,7 & 19 & 18,4 & 4 & 12,5 & \\
\hline Não & 14 & 93,3 & 84 & 81,6 & 28 & 87,5 & \\
\hline Cansaço durante as aulas & & & & & & & $\mathrm{p}^{(1)}=0,008^{*}$ \\
\hline Nunca / Raramente & 2 & 13,3 & 4 & 3,9 & - & - & \\
\hline Às vezes & 9 & 60,0 & 39 & 37,9 & 7 & 21,9 & \\
\hline Muitas vezes/ Sempre & 4 & 26,7 & 60 & 58,3 & 25 & 78,1 & \\
\hline Cochilos durante as aulas & & & & & & & $\mathrm{p}^{(1)}=0,002^{*}$ \\
\hline Nunca / Raramente & 11 & 73,3 & 59 & 57,3 & 8 & 25,0 & \\
\hline Às vezes & 4 & 26,7 & 28 & 27,2 & 12 & 37,5 & \\
\hline Muitas vezes/ Sempre & - & - & 16 & 15,5 & 12 & 37,5 & \\
\hline
\end{tabular}

(*) Associação significativa a 5\%

(1) Através do teste Exato de Fisher

(2) Através do teste Qui-quadrado de Pearson.

Trata-se de uma realidade preocupante, visto que a privação do sono que se inicia na juventude tende a se estender à vida do sujeito pelas grandes demandas acadêmicas e 
profissionais. Graduandos estão muitas vezes submetidos a um forte estresse, múltiplas atividades extracurriculares, pressão pela exigência de bom desempenho acadêmico e cumprimento da alta carga horária dos cursos. Tais fatores propiciam distúrbios do sono como a insônia crônica, que, por sua vez, impacta no desempenho das atividades acadêmicas e saúde dessa população, aumentando o índice de má qualidade de sono (SILVA et al., 2016).

\section{CONCLUSÕES}

Conclui-se que em relação ao desempenho acadêmico, evidencia-se a associação significativa da realização de provas finais, cansaço e cochilos nas aulas com a má qualidade do sono e presença de distúrbio do sono. Corroborando com a literatura no que diz respeito ao estilo de vida de universitários que favorecem o desenvolvimento de alterações relacionadas ao sono que por sua vez, impactam negativamente no desempenho acadêmico.

\section{REFERÊNCIAS}

ALMEIDA, J.O.S., et al. Day time sleepiness and sleep quality in physical therapy students. Conscientia e saúde 10(4) 20109. 2011.

Associação Brasileira Do Sono (ABS). Semana do sono 2018 - Respeite seu sono e siga seu ritmo. Cartilha do Sono. Brazil. 2018.

BARDINI, R., et al. Prevalência de sonolência excessiva diurna e fatores associados em adolescentes universitários do sul catarinense. Arq. Catarin Med 46 (1): 107-124. Santa Catarina. 2017.

FINIMUNDI, M., et al. Validação da escala de ritmo circadiano - ciclo vigília/sono para adolescentes. Rev. paul. Pediatr 30(3): 409-414. São Paulo. 2012.

MAGALHÃES, F. et al., orgs. Medicina da noite: da cronobiologia à prática clínica. Editora FIOCRUZ. Rio de Janeiro. ISBN 978-85-7541-336-4. 2007.

OWENS, J. Insufficient sleep in adolescents and young adults: an update on causes and consequences. Pediatrics. n.32, v.134,p. 921, 2014.

SANTOS, A. A., et al. Sono, fragilidade e cognição: estudo multicêntrico com idosos brasileiros. Rev. bras. Enferm. 66(3): 351-357. Brasília. 2013.

SCHNEIDER, M. L. M., et al. Morningness-eveningness, use of stimulants, and minor psychiatric disorders among undergraduate students. Int J Psych ol 46(1): 18-23. 2010.

Silva, G. M., et al. Qualidade do sono em estudantes do regime regular e internato médico. Revista Médica da UFPR 3(1): 19-24. 2016. 
STEA, T. H.; TORSTVEIT, M. K. Association of lifestyle habits and academic achievement in Norwegian adolescents: a cross-sectional study. BMC Public Health. n.14 , 829, 2014.

Valle, L. E. L. R., Valle, E. L. \& Reimao, R. Sono e aprendizagem. Rev. psicopedag. 26(80): 286-290. São Paulo. 2009.

Valle, L. E. L. R. Estresse e distúrbios do sono no desempenho de professores: saúde mental no trabalho. Biblioteca Dante Moreira Leite. São Paulo. 2011.

VASCONCELOS, H. C. A., et al. Correlação entre indicadores antropométricos e a qualidade do sono de universitários brasileiros. Rev. esc. enferm. 47(4): 852-859. USP, São Paulo. 2013. 